Article

\title{
Effectiveness of Streptococcus Pneumoniae Urinary Antigen Testing in Decreasing Mortality of COVID-19 Co-Infected Patients: A Clinical Investigation
}

\author{
Antonio Desai ${ }^{1,2, *(\mathbb{C})}$, Orazio Giuseppe Santonocito ${ }^{3}$, Giuseppe Caltagirone ${ }^{1,2}$, Maria Kogan ${ }^{1}$, \\ Federica Ghetti ${ }^{1}$, Ilaria Donadoni ${ }^{1}$, Francesca Porro ${ }^{1}$, Victor Savevski ${ }^{4}$, Dario Poretti ${ }^{3}$, \\ Michele Ciccarelli ${ }^{5}$, Filippo Martinelli Boneschi ${ }^{6,7,+}$ and Antonio Voza ${ }^{1,+}$ \\ 1 Emergency Department, Humanitas Clinical and Research Center, IRCCS, 20089 Milan, Italy; \\ giuseppe.caltagirone@humanitas.it (G.C.); maria.kogan@humanitas.it (M.K.); \\ federica.ghetti@humanitas.it (F.G.); ilaria.donadoni@humanitas.it (I.D.); francesca.porro@humanitas.it (F.P.); \\ antonio.voza@humanitas.it (A.V.) \\ 2 Department of Biomedical Sciences, Humanitas University, 20090 Pieve Emanuele, Italy \\ 3 Department of Diagnostic and Interventional Radiology, Humanitas Clinical and Research Center IRCCS, \\ Rozzano, 20089 Milan, Italy; giuseppe.santonocito@humanitas.it (O.G.S.); dario.poretti@humanitas.it (D.P.) \\ 4 Artificial Intelligence Center, Humanitas Clinical and Research Center, IRCCS, 20089 Milan, Italy; \\ victor.savevski@humanitas.it \\ 5 Pneumology Department, Humanitas Clinical and Research Center, IRCCS, 20089 Milan, Italy; \\ michele.ciccarelli@humanitas.it \\ 6 Dino Ferrari Centre, Neuroscience Section, Department of Pathophysiology and Transplantation (DEPT), \\ University of Milan, 20122 Milan, Italy; filippo.martinelli71@gmail.com \\ 7 Neurology Unit and MS Centre, Fondazione IRCCS Ca' Granda Ospedale Maggiore Policlinico, \\ 20122 Milan, Italy \\ * Correspondence: desaiantonio@gmail.com; Tel.: +39-0282-247-053 \\ + These 2 senior authors contributed equally to the work.
}

Received: 24 September 2020; Accepted: 27 October 2020; Published: 29 October 2020

check for updates

\begin{abstract}
Background and objectives: Streptococcus pneumoniae urinary antigen (u-Ag) testing has recently gained attention in the early diagnosis of severe and critical acute respiratory syndrome coronavirus-2/pneumococcal co-infection. The aim of this study is to assess the effectiveness of Streptococcus pneumoniae $\mathrm{u}-\mathrm{Ag}$ testing in coronavirus disease 2019 (COVID-19) patients, in order to assess whether pneumococcal co-infection is associated with different mortality rate and hospital stay in these patients. Materials and Methods: Charts, protocols, mortality, and hospitalization data of a consecutive series of COVID-19 patients admitted to a tertiary hospital in northern Italy during COVID-19 outbreak were retrospectively reviewed. All patients underwent Streptococcus pneumoniae $\mathrm{u}-\mathrm{Ag}$ testing to detect an underlying pneumococcal co-infection. Covid19+/u-Ag+ and Covid19+/u-Ag- patients were compared in terms of overall survival and length of hospital stay using chi-square test and survival analysis. Results: Out of 575 patients with documented pneumonia, $13 \%$ screened positive for the $\mathrm{u}-\mathrm{Ag}$ test. All $\mathrm{u}-\mathrm{Ag}+$ patients underwent treatment with Ceftriaxone and Azithromycin or Levofloxacin. Lopinavir/Ritonavir or Darunavir/Cobicistat were added in 44 patients, and hydroxychloroquine and low-molecular-weight heparin (LMWH) in 47 and 33 patients, respectively. All u-Ag+ patients were hospitalized. Mortality was $15.4 \%$ and $25.9 \%$ in $\mathrm{u}-\mathrm{Ag}+$ and $\mathrm{u}-\mathrm{Ag}$ - patients, respectively $(p=0.09)$. Survival analysis showed a better prognosis, albeit not significant, in u-Ag+ patients. Median hospital stay did not differ among groups ( 10 vs. 9 days, $p=0.71$ ). Conclusions: The routine use of Streptococcus pneumoniae $\mathbf{u}-\mathrm{Ag}$ testing helped to better target antibiotic therapy with a final trend of reduction in mortality of u-Ag+ COVID-19 patients having a concomitant pneumococcal infection. Randomized trials on larger cohorts are necessary in order to draw definitive conclusion.
\end{abstract}


Keywords: antibodies; bacterial infection 2; COVID-19; SARS-CoV-2; Streptococcus pneumoniae

\section{Introduction}

Bacterial co-infection is known to be associated with higher mortality in the setting of viral and parasitic diseases. This is due to severe inhibition of the host's immune system as well as an increased resistance to the antibacterial therapy [1-3]. The devastating effects of a bacterial pneumonia in determining serious and fatal outcomes are not a novelty, as have been previously described in detail in association to other pandemic and non-pandemic viruses [4-9]. Even in the context of a co-colonization, bacteria may become pathogenic when a viral-induced immunosuppression occurs. As for coronavirus disease 2019 (COVID-19), limited data regarding the rate of concomitant infection have been portrayed in recent studies, reporting a broad range of variability (ranging from $2.1 \%$ to $94.2 \%$ ) of co-infections and superinfections, most commonly bacterial [10-17]. Co-infection has been proven to have the highest incidence in severe-to-critical patients, in particular in those aged 15-44 and within 1-4 days of onset of COVID-19 disease [14]. Co-infection may also hinder an accurate diagnosis of severe acute respiratory syndrome coronavirus-2 (SARS-CoV-2) infection $[11,15,16]$. Streptococcus pneumoniae was found to be the most common pathogen associated with co-infection in these patients, followed by Klebsiella pneumoniae and Haemophilus influenzae [10-14]. Accordingly, an early diagnosis of S. pneumoniae and SARS-CoV-2 co-infection has been hypothesized to be an important factor in order prevent a series of potentially deadly complications in COVID-19 patients. The prophylactic use of pneumococcal conjugate and polysaccharide vaccines have even been recommended by some authors to decrease the risk of co-infection by the most common pathogens $[14,18,19]$. Nowadays, the presence of S. pneumoniae infection can be assessed by S. pneumoniae urinary antigen ( $\mathrm{u}-\mathrm{Ag}$ ) testing, a non-invasive, inexpensive test based on an immunochromatographic technique, and its rapid result can guide the choice of antibiotic regimen in the emergency department (ED) settings [20-23]. A recent study by Kim and colleagues strongly advised the routine testing for non-SARS-CoV-2 respiratory pathogens during the COVID-19 pandemic in order to improve the clinical management of these patients, ultimately providing clinical benefits [11].

The aim of this retrospective cross-sectional study is to assess the effectiveness of the routine use of S. pneumoniae $\mathrm{u}$-Ag testing in decreasing the overall mortality and in-hospital length of stay of COVID-19 patients with a pneumococcal co-infection.

\section{Materials and Methods}

All subjects gave their informed consent for inclusion before they participated in the study. The study was conducted in accordance with the Declaration of Helsinki, and the protocol was approved by the Ethics Committee of Humanitas Clinical and Research Center, a tertiary referral Hospital in Milan located in Lombardy Region in northern Italy. Medical charts, management protocols, therapies, and overall morbidity and mortality data of a consecutive series of patients admitted to the ED from April to September 2020 with a diagnosis of SARS-CoV-2 infection were retrospectively reviewed. Data were analyzed in order to assess the role of S. pneumoniae $\mathrm{u}-\mathrm{Ag}$ testing in the diagnosis of pneumococcal co-infection, as well as assessment of therapeutic protocols and the outcome in terms of length of hospital stay and survival analysis.

\section{Outcome Measures}

We compared Covid19+/u-Ag+ patients with Covid19+/u-Ag- in terms of overall survival and in-hospital length of stay. Differences in categorical responses between the two groups and in the pattern of computed tomography (CT) distribution were analyzed using a chi-square test performed on commercially available software (IBM SPSS software version 26.0). A survival analysis was also performed. 
Data were reported according to the Strengthening the Reporting of Observational Study in Epidemiology statement [24].

\section{Results}

\subsection{Criteria for Suspicion of SARS-CoV-2 Infection and Emergency Management}

Presumed diagnosis was based on predetermined signs and symptoms suggestive of infection, namely fever, dry cough, sore throat, fatigue, dyspnea, shortness of breath, chest pain, diarrhea, rash or discoloration of fingers or toes, and loss of sense of taste or smell. In patients presenting with previously described signs and symptoms, mean oxygen saturation (SpO2) and arterial oxygen partial pressure to fractional inspired oxygen ratio ( $\mathrm{P} / \mathrm{F}$ ratio) were measured. Reverse transcriptase-polymerase chain reaction (RT-PCR) for SARS-CoV-2 was routinely performed on nasopharyngeal swab along with S. pneumoniae $\mathrm{u}-\mathrm{Ag}$ testing. Diagnosis of SARS-CoV-2 infection on RT-PCR was based on the World Health Organization interim guidance [25]. Chest CT scans were performed in all patients and independently reviewed by two expert radiologists, who classified the results in four different categories. Pediatric patients were excluded from the cohort, as those were managed in a dedicated pediatric ED. In case of confirmed SARS-CoV-2 infection and documented pneumonia, an antibiotic regimen was administered, and antiviral therapy was added to the regimen in case symptoms presented inferior to a 7-day period. In addition, hydroxychloroquine was used as an immune modulator in COVID-19 patients and administered only after the electrocardiographic exclusion of arrhythmias. Low-molecular-weight heparin (LMWH) was also prophylactically prescribed. None of the patients were treated with steroids.

\subsection{Antibiotic Protocol}

Antibiotic protocol included a combination of Ceftriaxone $2 \mathrm{~g}$ IM/IV twice daily for 7-10 days and Azithromycin $500 \mathrm{mg}$ PO once daily for 3 consecutive days. When one or both drugs were contraindicated, Levofloxacin stand-alone $750 \mathrm{mg}$ PO/IV once daily for 5 days was administered. In case of acute bacterial exacerbation of an already known chronic bronchitis, Levofloxacin $500 \mathrm{mg}$ $\mathrm{PO} / \mathrm{IV}$ once daily for $\geq 7$ days was the choice. Doses were adjusted for renal insufficiency case-by-case based on creatinine and calculated glomerular filtration rate.

\subsection{Antiviral Protocol}

The off-label antiviral protocol entailed Lopinavir/Ritonavir $200 \mathrm{mg} / 100 \mathrm{mg}$ PO twice daily or Darunavir/Cobicistat 800/150 mg PO once daily, both administered until clinical improvement.

\subsection{Hydroxychloroquine}

Hydroxychloroquine $200 \mathrm{mg}$ PO twice a day was also started by default in all patients immediately after COVID-19 diagnosis.

\subsection{Low Molecular Weight Heparin}

Enoxaparin or Nadroparin calcium were used for prophylaxis once daily with a dosage adjusted based on weight and renal function.

\subsection{Indications for Hospitalization}

The need for hospitalization was evaluated case-by-case, considering multiple factors such as age, clinical status, respiratory parameters, and comorbidities. CURB65, which is a clinical algorithm validated for predicting mortality in community acquired pneumonia (CAP) and infection of any site and pneumonia severity index (PSI)/Pneumonia Patient Outcome Research Team (PORT) scores were used $[26,27]$. 


\subsection{Incidence of SARS-CoV-2 Infection and SARS-CoV-2 and Pneumococcal Co-Infection}

A total of 1247 consecutive cases of suspected SARS-CoV-2 infection were admitted to the ED, 575 of whom resulted positive for the virus $(46 \%)$. S. pneumoniae $\mathrm{u}-\mathrm{Ag}$ testing was performed in 536 patients (93\%) of confirmed COVID-19 cases. Sixty-eight patients (13\%) were diagnosed with co-infection (Covid19+/u-Ag+). Characteristics of patients with confirmed coinfection included an average age of 62.9 years (SD: 12.8), of whom 47 patients were $>60$ years old $(69.1 \%$ ) and male/female ratio of 1 . Among Covid19+/u-Ag+ patients, we identified a lower number of males compared to u-Ag- (50\% vs. $68.4 \% ; p=0.003)$. Most common comorbidities were hypertension (35.5\%), cardiovascular $(25 \%)$, respiratory $(11.3 \%)$, and malignancy $(14.5 \%)$. Clinical features of Covid19+/u-Ag+ patients included fever in $60(88 \%)$, cough in $41(60 \%)$, dyspnea in $34(50 \%)$, and diarrhea in $10(15 \%)$. Mean SpO2 was $91.8 \%$, with an underlying respiratory alkalosis in $74 \%$ of cases. $\mathrm{P} / \mathrm{F}$ ratio was $>300$ in 41 patients $(60 \%)$, between 300 and 200 in 20 patients $(30 \%)$, and $<200$ in $7(10 \%)$ cases.

\subsection{Chest CT Scan Findings}

None of COVID-19+/u-Ag- patients presented focal opacities on chest CT scan in comparison with 3 COVID-19+/u-Ag+ group ( $p=0.001)$. Conversely, four main CT patterns were detected in COVID-19+/u-Ag+ group as follows: normal (8.8\%), ground glass opacification (GGO) $(67.6 \%)$, GGO and multifocal consolidative opacities (19.2\%), and focal opacities (4.4\%). On a second chest CT scan, performed in 47 patients at an average interval of 35.2 days \pm from the first CT scan, the proportion of normal CT scans increased to $36.2 \%$, GGO decreased (34\%), and GGO and multifocal consolidative opacities increased to $29.8 \%$. Among COVID-19+/u-Ag+, a lower mortality was seen in the group with solely GGO as compared to the other groups ( $8.8 \%$ vs. $21.7 \% ; p=0.07)$. Among patients with an initially normal CT scan, two patients had a worsening clinical course resulting in hospital mortality: the first was an 82-year-old male, in this case the second CT scan, performed 39 days later, showed GGO and multi-lobar involvement, whereas the second patient was a 38-year-old female who died 7 days after the hospitalization.

\subsection{Therapeutic Algorithms and Clinical Course}

Antibiotic treatment was given to all patients, whereas antiviral protocol was implemented in $45 \mathrm{u}-\mathrm{Ag}+$ patients $(65.7 \%)$. Hydroxychloroquine and Enoxaparin, or alternatively Nadroparin, were administered in $47(70.1 \%)$ and 33 patients (80.7\%), respectively. COVID-19+/u-Ag+ group had a lower percentage of patients who underwent treatment with Hydroxychloroquine (70.1\% vs. 80.7\%; $p=0.04)$. Eight patients (12\%) required supplementary oxygen, four of whom $(50 \%)$ have been subjected to orotracheal intubation performed in the ED. All COVID-19+/u-Ag+ patients were hospitalized. Transfer to an Intensive Care Unit was necessary in $14.7 \%$ of cases.

\subsection{Overall Survival}

Overall mortality was $24.6 \%$. Mortality was lower in Covid $19+/ \mathrm{u}-\mathrm{Ag}+$ patients $(15.4 \%$ vs. $25.9 \%$; $p=0.09$ ), and survival analysis confirmed a better prognosis in the prior group when compared to Covid19+/u-Ag- patients. Nevertheless, the data were not significant (log-rank test: $p=0.09$; $75 \%$ percentile of survival: 12 days for Covid19+/u-Ag-, 16 days for Covid19+/u-Ag+) (Figure 1). 


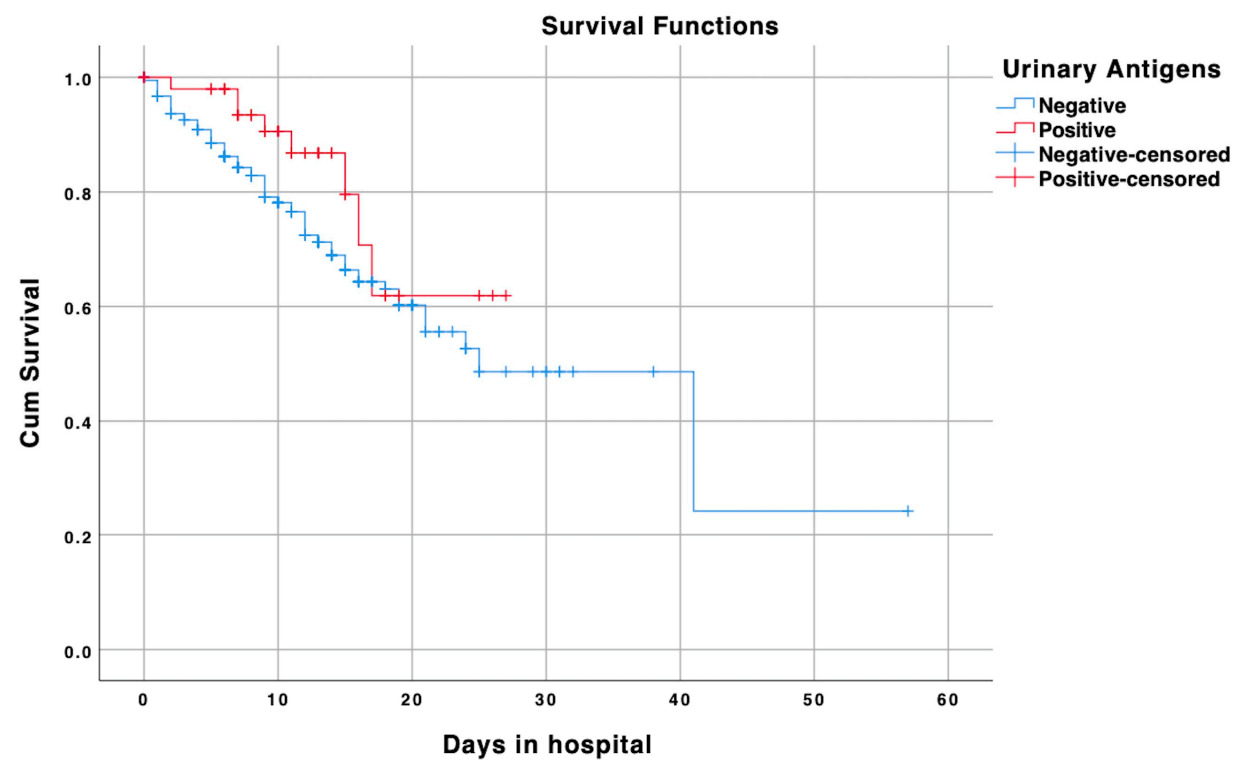

Figure 1. Survival analysis of Covid19+/u-Ag+ (red line) and Covid19+/u-Ag- (blue line) groups after emergency department admission. Censored cases are also shown for either groups: positive censored cases represent the end of follow-up of COVID-19 patients with positive urinary antigens, while negative censored cases represent the end of follow-up of COVID-19 patients with negative urinary antigens.

\subsection{In-Hospital Length of Stay}

Median in-hospital stay was 10 days (interquartile range (IQR), 1-27 in COVID-19+/u-Ag+ patients, and 9 days in the COVID-19+/u-Ag-group (IQR $1-57, p=0.71$ ). Table 1 summarizes the overall data of the patients' cohort (Table 1).

Table 1. Clinical features of patients stratified by pneumococcal urinary antigen positivity.

\begin{tabular}{cccc}
\hline Data & Positive $(\boldsymbol{n}=\mathbf{6 8})$ & Negative $(\boldsymbol{n = 4 6 8 )}$ & $p$-Value \\
\hline Age, mean (SD), (range) & $62.9(12.8)(28-92)$ & $65.1(14.8)(27-93)$ & $p=0.19$ \\
Male, $n$ (\%) & $34 / 68(50 \%)$ & $320 / 468(68.4 \%)$ & $p=0.003$ \\
Comorbidities, median (IQR), (range) & $1(1)(0-7)$ & $1(1)(0-10)$ & $p=0.67$ \\
Antivirals, $n(\%)$ & $44 / 67(65.7 \%)$ & $325 / 463(70.2 \%)$ & $p=0.45$ \\
Antibiotics, $n(\%)$ & $67 / 67(100 \%)$ & $427 / 464(92 \%)$ & $p=0.02$ \\
Hydroxychloroquine, $n(\%)$ & $47 / 67(70.1 \%)$ & $373 / 462(80.7 \%)$ & $p=0.04$ \\
LMWH, $n$ (\%) & $33 / 67(49.3 \%)$ & $188 / 461(40.8 \%)$ & $p=0.18$ \\
Time to ED (days), median (IQR), (range) & $5(7)(0-25)$ & $7(7)(0-35)$ & $p=0.72$ \\
LOS in days, median (IQR), (range] & $10(7)(1-27)$ & $9(8)(1-57)$ & $p=0.71$ \\
Chest CT scan: normal & $6(8.8 \%)$ & $21(4.5 \%)$ & \\
GGO & $46(67.6 \%)$ & $324(69.2 \%)$ & $p<0.001$ \\
GGO and multifocal consolidative opacities & $13(19.2 \%)$ & $123(26.3 \%)$ & \\
Focal opacity & $3(4.4 \%)$ & 0 & $p=0.09$ \\
In-hospital death $(n, \%)$ & $8 / 52(15.4 \%)$ & $98 / 378(25.9 \%)$ &
\end{tabular}

LMWH: Low Molecular Weight Heparin; ED: Emergency Department; LOS: Length Of In-hospital Stay; GGO: Ground Glass Opacities.

\section{Discussion}

In the current study we retrospectively reviewed a cohort of patients consecutively admitted to a tertiary hospital located in Northern Italy during the COVID-19 pandemic, with the aim to assess whether the early detection of SARS-CoV-2 and pneumococcal co-infection by S. pneumoniae u-Ag testing in ED setting is associated with a difference in mortality and length of hospital stay. Based on our findings, none of the previous were significantly influenced by the test. 
Bacterial co-infection has been reported to have a lower rate in COVID-19 patients as compared to other respiratory viral infections; the underlying factors for this finding are still largely unknown [28-32]. Nevertheless, SARS-CoV-2 and S. pneumoniae co- or super-infection has been reported to be an emerging source of concern, as it is associated with a worse or even fatal outcome in these patients [11,33-35]. The presence of a co-infection at hospital admission may mask the diagnosis of COVID-19. Lai and colleagues stressed that laboratory and imaging findings alone cannot help to distinguish co-infection from COVID-19, and that newly developed syndromic multiplex panels incorporating SARS-CoV-2 are necessary in order to improve early detection of co-infection [34]. Zahariadis and colleagues reported that diagnostic assays established for the most common pulmonary pathogens have several limitations, and the ruling out of SARS-CoV-2 by ruling in another pulmonary pathogen represents a non-negligible risk [35]. Notably, in 2004, Beadling and colleagues clarified that bacterial co- or super-infection of viral acute infections affects the outcome negatively through a severe alteration of the immune response; these include impaired natural killer cells and macrophage functions, co-activation of T cells, and lastly, hypersecretion of inflammatory cytokines. All of the previously depicted contribute to a lethal immunopathology [3]. Interestingly, similar cellular pathways have been reported in the pathogenesis of some central nervous system infections in which S. pneumoniae $\mathrm{u}$-Ag has been thought as a potentially effective tool to detect an underlying pneumococcal infection in COVID-19 patients [36-46]. Streptococcus pneumoniae is an opportunistic Gram-positive pathogen that colonizes the mucosal surfaces of the human upper respiratory tract and establishes a commensal relationship with the host [47]. It is the most common pathogen responsible for community-acquired pneumonia [48]. In addition, in COVID-19, S. pneumoniae infection has been hypothesized to have an aggressive clinical course especially in some categories of patients considered at higher risk of mortality, namely those aged $>65$ years old, diabetics, and patients with a history of chronic alcohol abuse or immunosuppression $[49,50]$. Accordingly, an early diagnosis of pneumococcal infection may lead to tailored antibiotic regimen choice, which will allow optimal clinical management in high risk patients in addition to cost reduction. In our series, the incidence of $S$. pneumoniae infection detected with $\mathrm{u}$-Ag testing was very similar to the one observed in a cohort of 1110 patients with clinical and radiographic evidence of pneumonia admitted to the ED of seven Utah hospitals in over two years, prior to COVID-19 pandemic [51]. Noteworthy, the evidence of pneumococcal infection ultimately led to the addition of Levofloxacin or Azithromycin to the treatment regimen of co-infected patients. Taking into consideration the unquestionable superiority of the most common invasive and non-invasive examinations in obtaining the microbiological evidence of pneumococcal infection, S. pneumoniae $\mathrm{u}-\mathrm{Ag}$ testing has been associated with an average sensitivity and specificity of $70 \%$ and $95 \%$, respectively [20-22,51-53]. This test is rapid, non-invasive, easily accessible, and repeatable. Recently, Charton and colleagues found that age, immunosuppressive factors, typical pneumococcal symptoms, and PSI scores correlate with a positive S. pneumoniae u-Ag test [53]. All the aforementioned factors led us to hypothesize that the routine use of $S$. pneumoniae u-Ag testing, implemented at our ED since the beginning of COVID-19 outbreak, might have affected the outcome and length of hospital stays in SARS-CoV-2/S. pneumoniae co-infected patients. Our data did not confirm this hypothesis; thus, we cannot recommend our management protocol in its integral form. Nevertheless, it is of relevance to consider the findings reported in our survival analysis, as they show a tendency for a better prognosis in Covid19+/u-Ag+ patients when compared to Covid19+/u-Ag-. Doubts do still exist by the authors about the implementation of a prospective and randomized trial involving a larger cohort of patients, which may lead to a different conclusion regarding the beneficial effect of S. pneumoniae co-infection on mortality rate and length of hospital stay.

\section{Limitations}

Limitations of this study include its retrospective nature, small sample size, and lack of blood or pleural fluid culture to confirm the diagnosis of S. pneumoniae co-infection. In part, these limitations are shared with other recent studies, as many were caused by the exceptional situation generated 
by the SARS-CoV-2 pandemic outbreak. It is worthwhile to mention the different and changing therapeutic protocols adopted during the management of COVID-19, in accordance to what divulged and recommended by the World Health Organization in the acute phase of the pandemic, which has unavoidably introduced biases in this and other similar studies. The timely treatment itself with targeted antibiotics in all patients having SARS-CoV-2 infection and documented pneumonia may have improved the prognosis of the co-infected patients, leading to an underestimation of the effectiveness of S. pneumoniae $\mathrm{u}-\mathrm{Ag}$ test.

\section{Conclusions}

The use of S. pneumoniae u-Ag testing, aimed at an early diagnosis of SARS-CoV-2 and S. pneumoniae co-infection, did not significantly affected the overall mortality and length of hospital stay of COVID-19 patients. Its routine use at hospital admission in the ED setting cannot therefore be recommended. However, in light of the multiple theoretical advantages coming from the ease, reliability, and cost-effectiveness of this test, as well as the trend toward statistical significance of reported data, further study and randomized trials are worthwhile to be implemented, since they may theoretically lead to different results.

Author Contributions: On behalf of Humanitas COVID-19 Task Force: Conceptualization, A.D. and G.C.; methodology, F.M.B.; software, V.S.; validation, F.M.B., F.G., I.D., and F.P.; formal analysis, F.M.B.; investigation, A.D. and A.V.; data curation, M.C. and O.G.S.; writing — original draft preparation, A.D. and M.K.; writing-review and editing, A.D., A.V., and F.M.B.; visualization, D.P.; supervision, F.M.B. and A.V. All authors have read and agreed to the published version of the manuscript.

Funding: This research received no external funding.

Acknowledgments: Humanitas Clinical and Research Center.

Conflicts of Interest: The authors declare no conflict of interest.

\section{References}

1. Li, X.X.; Zhou, X.N. Co-infection of tuberculosis and parasitic diseases in humans: A systematic review. Parasit. Vectors 2013, 6, 79. [CrossRef] [PubMed]

2. Guo, L.; Wei, D.; Zhang, X.; Wu, Y.; Li, Q.; Zhou, M.; Qu, J. Clinical Features Predicting Mortality Risk in Patients With Viral Pneumonia: The MuLBSTA Score. Front. Microbiol. 2019, 10, 2752. [CrossRef] [PubMed]

3. Beadling, C.; Slifka, M.K. How do viral infections predispose patients to bacterial infections? Curr. Opin. Infect. Dis. 2004, 17, 185-191. [CrossRef] [PubMed]

4. MacIntyre, C.R.; Chughtai, A.A.; Barnes, M.; Ridda, I.; Seale, H.; Toms, R.; Heywood, A. The role of pneumonia and secondary bacterial infection in fatal and serious outcomes of pandemic influenza a(H1N1)pdm09. BMC Infect. Dis. 2018, 18, 637. [CrossRef] [PubMed]

5. Chertow, D.S.; Memoli, M.J. Bacterial coinfection in influenza: A grand rounds review. JAMA 2013, 309, 275-282. [CrossRef] [PubMed]

6. Klein, E.Y.; Monteforte, B.; Gupta, A.; Jiang, W.; May, L.; Hsieh, Y.H.; Dugas, A. The frequency of influenza and bacterial coinfection: A systematic review and meta-analysis. Influenza Other Respir. Viruses 2016, 10, 394-403. [CrossRef] [PubMed]

7. Bosch, A.A.; Biesbroek, G.; Trzcinski, K.; Sanders, E.A.; Bogaert, D. Viral and bacterial interactions in the upper respiratory tract. PLoS Pathog. 2013, 9, e1003057. [CrossRef] [PubMed]

8. Brundage, J.F. Interactions between influenza and bacterial respiratory pathogens: Implications for pandemic preparedness. Lancet Infect. Dis. 2006, 6, 303-312. [CrossRef]

9. Pasman, L. The complication of coinfection. Yale J. Biol. Med. 2012, 85, 127-132. [PubMed]

10. Garcia-Vidal, C.; Sanjuan, G.; Moreno-García, E.; Puerta-Alcalde, P.; Garcia-Pouton, N.; Chumbita, M.; Fernandez-Pittol, M.; Pitart, C.; Inciarte, A.; Bodro, M.; et al. Incidence of co-infections and superinfections in hospitalized patients with COVID-19: A retrospective cohort study. Clin. Microbiol. Infect. 2020. [CrossRef]

11. Kim, D.; Quinn, J.; Pinsky, B.; Shah, N.H.; Brown, I. Rates of Co-infection Between SARS-CoV-2 and Other Respiratory Pathogens. JAMA 2020, 323, 2085-2086. [CrossRef] [PubMed] 
12. Richardson, S.; Hirsch, J.S.; Narasimhan, M.; Crawford, J.M.; McGinn, T.; Davidson, K.W.; Northwell, C.-R.C.; Barnaby, D.P.; Becker, L.B.; Chelico, J.D.; et al. Presenting Characteristics, Comorbidities, and Outcomes Among 5700 Patients Hospitalized With COVID-19 in the New York City Area. JAMA 2020, 323, 2052-2059. [CrossRef] [PubMed]

13. Chen, N.; Zhou, M.; Dong, X.; Qu, J.; Gong, F.; Han, Y.; Qiu, Y.; Wang, J.; Liu, Y.; Wei, Y.; et al. Epidemiological and clinical characteristics of 99 cases of 2019 novel coronavirus pneumonia in Wuhan, China: A descriptive study. Lancet 2020, 395, 507-513. [CrossRef]

14. Zhu, X.; Ge, Y.; Wu, T.; Zhao, K.; Chen, Y.; Wu, B.; Zhu, F.; Zhu, B.; Cui, L. Co-infection with respiratory pathogens among COVID-2019 cases. Virus Res. 2020, 285, 198005. [CrossRef] [PubMed]

15. Lansbury, L.; Lim, B.; Baskaran, V.; Lim, W.S. Co-infections in people with COVID-19: A systematic review and meta-analysis. J. Infect. 2020, 81, 266-275. [CrossRef]

16. Contou, D.; Claudinon, A.; Pajot, O.; Micaelo, M.; Longuet Flandre, P.; Dubert, M.; Cally, R.; Logre, E.; Fraisse, M.; Mentec, H.; et al. Bacterial and viral co-infections in patients with severe SARS-CoV-2 pneumonia admitted to a French ICU. Ann. Intensive Care 2020, 10, 119. [CrossRef]

17. Thindwa, D.; Garcia Quesada, M.; Liu, Y.; Bennett, J.; Cohen, C.; Knoll, M.D.; von Gottberg, A.; Hayford, K.; Flasche, S. Use of seasonal influenza and pneumococcal polysaccharide vaccines in older adults to reduce COVID-19 mortality. Vaccine 2020, 38, 5398-5401. [CrossRef]

18. Mendelson, M. Could enhanced influenza and pneumococcal vaccination programs help limit the potential damage from SARS-CoV-2 to fragile health systems of southern hemisphere countries this winter? Int J. Infect. Dis. 2020, 94, 32-33. [CrossRef]

19. Gutiérrez, F.; Masiá, M.; Rodríguez, J.C.; Ayelo, A.; Soldán, B.; Cebrián, L.; Mirete, C.; Royo, G.; Hidalgo, A.M. Evaluation of the immunochromatographic Binax NOW assay for detection of Streptococcus pneumoniae urinary antigen in a prospective study of community-acquired pneumonia in Spain. Clin. Infect. Dis. 2003, 36, 286-292. [CrossRef]

20. Rosón, B.; Fernández-Sabé, N.; Carratalà, J.; Verdaguer, R.; Dorca, J.; Manresa, F.; Gudiol, F. Contribution of a urinary antigen assay (Binax NOW) to the early diagnosis of pneumococcal pneumonia. Clin. Infect. Dis. 2004, 38, 222-226. [CrossRef]

21. Honoré, S.; Trillard, M.; Ould-Hocine, Z.; Lesprit, P.; Deforges, L.; Legrand, P. Contribution of urinary pneumococcal antigen detection combined with the research of legionella antigen for diagnosis of pneumonia in hospitalized patients. Pathol. Biol. (Paris) 2004, 52, 429-433. [CrossRef] [PubMed]

22. Molinos, L.; Zalacain, R.; Menéndez, R.; Reyes, S.; Capelastegui, A.; Cillóniz, C.; Rajas, O.; Borderías, L.; Martín-Villasclaras, J.J.; Bello, S.; et al. Sensitivity, Specificity, and Positivity Predictors of the Pneumococcal Urinary Antigen Test in Community-Acquired Pneumonia. Ann. Am. Thorac. Soc. 2015, 12, 1482-1489. [CrossRef]

23. Von Elm, E.; Altman, D.G.; Egger, M.; Pocock, S.J.; Gøtzsche, P.C.; Vandenbroucke, J.P. The Strengthening the Reporting of Observational Studies in Epidemiology (STROBE) statement: Guidelines for reporting observational studies. Lancet 2007, 370, 1453-1457. [CrossRef]

24. World Health Organization. Clinical management of severe acute respiratory infection when novel coronavirus (2019-nCoV) infection is suspected: Interim guidance. In Clinical Management of Severe Acute Respiratory Infection When Novel Coronavirus (2019-nCoV) Infection is Suspected: Interim Guidance; World Health Organization: Geneva, Switzerland, 2020; p. 21.

25. Fine, M.J.; Auble, T.E.; Yealy, D.M.; Hanusa, B.H.; Weissfeld, L.A.; Singer, D.E.; Coley, C.M.; Marrie, T.J.; Kapoor, W.N. A prediction rule to identify low-risk patients with community-acquired pneumonia. N. Engl. J. Med. 1997, 336, 243-250. [CrossRef] [PubMed]

26. Lim, W.S.; van der Eerden, M.M.; Laing, R.; Boersma, W.G.; Karalus, N.; Town, G.I.; Lewis, S.A.; Macfarlane, J.T. Defining community acquired pneumonia severity on presentation to hospital: An international derivation and validation study. Thorax 2003, 58, 377-382. [CrossRef] [PubMed]

27. Burrell, A.; Huckson, S.; Pilcher, D.V. ICU Admissions for Sepsis or Pneumonia in Australia and New Zealand in 2017. N. Engl. J. Med. 2018, 378, 2138-2139. [CrossRef] [PubMed]

28. Martin-Loeches, I.; M, J.S.; Vincent, J.L.; Alvarez-Lerma, F.; Bos, L.D.; Solé-Violán, J.; Torres, A.; Rodriguez, A. Increased incidence of co-infection in critically ill patients with influenza. Intensive Care Med. 2017, 43, 48-58. [CrossRef] 
29. Garcia-Vidal, C.; Barba, P.; Arnan, M.; Moreno, A.; Ruiz-Camps, I.; Gudiol, C.; Ayats, J.; Ortí, G.; Carratalà, J. Invasive aspergillosis complicating pandemic influenza A (H1N1) infection in severely immunocompromised patients. Clin. Infect. Dis. 2011, 53, e16-e19. [CrossRef]

30. Schauwvlieghe, A.; Rijnders, B.J.A.; Philips, N.; Verwijs, R.; Vanderbeke, L.; Van Tienen, C.; Lagrou, K.; Verweij, P.E.; Van de Veerdonk, F.L.; Gommers, D.; et al. Invasive aspergillosis in patients admitted to the intensive care unit with severe influenza: A retrospective cohort study. Lancet Respir. Med. 2018, 6, 782-792. [CrossRef]

31. Cocco, A.; Amami, P.; Desai, A.; Voza, A.; Ferreli, F.; Albanese, A. Neurological features in SARS-CoV-2-infected patients with smell and taste disorder. J. Neurol. 2020, 1-3. [CrossRef]

32. Lin, D.; Liu, L.; Zhang, M.; Hu, Y.; Yang, Q.; Guo, J.; Guo, Y.; Dai, Y.; Xu, Y.; Cai, Y.; et al. Co-infections of SARS-CoV-2 with multiple common respiratory pathogens in infected patients. Sci. China Life Sci. 2020, 63, 606-609. [CrossRef] [PubMed]

33. Lai, C.C.; Wang, C.Y.; Hsueh, P.R. Co-infections among patients with COVID-19: The need for combination therapy with non-anti-SARS-CoV-2 agents? J. Microbiol. Immunol. Infect. 2020, 53, 505-512. [CrossRef] [PubMed]

34. Zahariadis, G.; Gooley, T.A.; Ryall, P.; Hutchinson, C.; Latchford, M.I.; Fearon, M.A.; Jamieson, F.B.; Richardson, S.; Kuschak, T.; Mederski, B. Risk of ruling out severe acute respiratory syndrome by ruling in another diagnosis: Variable incidence of atypical bacteria coinfection based on diagnostic assays. Can. Respir. J. 2006, 13, 17-22. [CrossRef] [PubMed]

35. Luzzi, S.; Crovace, A.M.; Del Maestro, M.; Giotta Lucifero, A.; Elbabaa, S.K.; Cinque, B.; Palumbo, P.; Lombardi, F.; Cimini, A.; Cifone, M.G.; et al. The cell-based approach in neurosurgery: Ongoing trends and future perspectives. Heliyon 2019, 5, e02818. [CrossRef] [PubMed]

36. Savioli, G.; Ceresa, I.F.; Macedonio, S.; Gerosa, S.; Belliato, M.; Iotti, G.A.; Luzzi, S.; Del Maestro, M.; Mezzini, G.; Giotta Lucifero, A.; et al. Trauma Coagulopathy and Its Outcomes. Medicina (Kaunas) 2020, 56, 205. [CrossRef] [PubMed]

37. Bellantoni, G.; Guerrini, F.; Del Maestro, M.; Galzio, R.; Luzzi, S. Simple schwannomatosis or an incomplete Coffin-Siris? Report of a particular case. eNeurologicalSci 2019, 14, 31-33. [CrossRef]

38. Luzzi, S.; Elia, A.; Del Maestro, M.; Elbabaa, S.K.; Carnevale, S.; Guerrini, F.; Caulo, M.; Morbini, P.; Galzio, R. Dysembryoplastic Neuroepithelial Tumors: What You Need to Know. World Neurosurg. 2019, 127, $255-265$. [CrossRef] [PubMed]

39. Giotta Lucifero, A.; Luzzi, S.; Brambilla, I.; Guarracino, C.; Mosconi, M.; Foiadelli, T.; Savasta, S. Gene therapies for high-grade gliomas: From the bench to the bedside. Acta Biomed. 2020, 91, 32-50. [CrossRef]

40. Giotta Lucifero, A.; Luzzi, S.; Brambilla, I.; Schena, L.; Mosconi, M.; Foiadelli, T.; Savasta, S. Potential roads for reaching the summit: An overview on target therapies for high-grade gliomas. Acta Biomed. 2020, 91, 61-78. [CrossRef]

41. Giotta Lucifero, A.; Luzzi, S.; Brambilla, I.; Trabatti, C.; Mosconi, M.; Savasta, S.; Foiadelli, T. Innovative therapies for malignant brain tumors: The road to a tailored cure. Acta Biomed. 2020, 91, 5-17. [CrossRef]

42. Luzzi, S.; Demasi, M.; Lucifero, A.G.; Simoncelli, A.; Carnevale, S.; Morbini, P.; Crovace, A.M.; Tartaglia, N.; Ambrosi, A. An underrated copmlication of the organs' transplantations. Ann. Ital. Chir. 2020, 91, 298-309. [PubMed]

43. Luzzi, S.; Giotta Lucifero, A.; Brambilla, I.; Magistrali, M.; Mosconi, M.; Savasta, S.; Foiadelli, T. Adoptive immunotherapies in neuro-oncology: Classification, recent advances, and translational challenges. Acta Biomed. 2020, 91, 18-31. [CrossRef] [PubMed]

44. Luzzi, S.; Giotta Lucifero, A.; Brambilla, I.; Semeria Mantelli, S.; Mosconi, M.; Foiadelli, T.; Savasta, S. Targeting the medulloblastoma: A molecular-based approach. Acta Biomed. 2020, 91, 79-100. [CrossRef] [PubMed]

45. Luzzi, S.; Giotta Lucifero, A.; Brambilla, I.; Trabatti, C.; Mosconi, M.; Savasta, S.; Foiadelli, T. The impact of stem cells in neuro-oncology: Applications, evidence, limitations and challenges. Acta Biomed. 2020, 91, 51-60. [CrossRef] [PubMed]

46. Weiser, J.N.; Ferreira, D.M.; Paton, J.C. Streptococcus pneumoniae: Transmission, colonization and invasion. Nat. Rev. Microbiol. 2018, 16, 355-367. [CrossRef] [PubMed]

47. Dion, C.F.; Ashurst, J.V. Streptococcus Pneumoniae. In StatPearls; StatPearls Publishing LLC: Treasure Island, FL, USA, 2020. 
48. (ANSM), Agence nationale de sécurité du médicament et des produits de santé. Antibiothérapie par voie Générale Dans les Infections Respiratoires Basses de l'adulte-Mise au Point. Available online: https://ansm.sante.fr/content/search?SearchText=Mise+au+point.+Antibiothérapie+par+ voie+générale+dans+les+infections+respiratoires+basses+de+l (accessed on 13 July 2010).

49. Austrian, R.; Gold, J. Pneumococcal bacteremia with especial reference to bacteremic pneumococcal pneumonia. Ann. Intern. Med. 1964, 60, 759-776. [CrossRef] [PubMed]

50. West, D.M.; McCauley, L.M.; Sorensen, J.S.; Jephson, A.R.; Dean, N.C. Pneumococcal urinary antigen test use in diagnosis and treatment of pneumonia in seven Utah hospitals. ERJ Open Res. 2016, 2, 00011-02016. [CrossRef] [PubMed]

51. Metlay, J.P.; Waterer, G.W.; Long, A.C.; Anzueto, A.; Brozek, J.; Crothers, K.; Cooley, L.A.; Dean, N.C.; Fine, M.J.; Flanders, S.A.; et al. Diagnosis and Treatment of Adults with Community-acquired Pneumonia. An Official Clinical Practice Guideline of the American Thoracic Society and Infectious Diseases Society of America. Am. J. Respir. Crit. Care Med. 2019, 200, e45-e67. [CrossRef]

52. Moine, P.; Vercken, J.B.; Chevret, S.; Chastang, C.; Gajdos, P. Severe community-acquired pneumonia. Etiology, epidemiology, and prognosis factors. French Study Group for Community-Acquired Pneumonia in the Intensive Care Unit. Chest 1994, 105, 1487-1495. [CrossRef]

53. Charton, F.; Conan, P.L.; Le Floch, H.; Bylicki, O.; Gaspard, W.; Soler, C.; Margery, J.; Rivière, F. Evaluation of pneumococcal urinary antigen testing for respiratory tract infection investigations. Med. Mal. Infect. 2020, 50, 57-62. [CrossRef]

Publisher's Note: MDPI stays neutral with regard to jurisdictional claims in published maps and institutional affiliations.

(C) 2020 by the authors. Licensee MDPI, Basel, Switzerland. This article is an open access article distributed under the terms and conditions of the Creative Commons Attribution (CC BY) license (http://creativecommons.org/licenses/by/4.0/). 